\title{
Prognostic Value of Thyroid Transcription Factor-1 Expression in Patients with Advanced Lung Adenocarcinoma
}

\author{
ROLANDAS ZABLOCKIS ${ }^{1,2}$, EDVARDAS ŽURAUSKAS ${ }^{3,4}$, \\ EDVARDAS DANILA ${ }^{1,2}$ and VYGANTAS GRUSLYS $S^{1,2}$ \\ ${ }^{1}$ Clinic of Chest Diseases, Immunology and Allergology, Institute of Clinical Medicine, ${ }^{3}$ Department of Pathology,
Forensic Medicine and Pharmacology, Institute of Biomedical Sciences, Vilnius University, Vilnius, Lithuania;
${ }^{2}$ Centre of Pulmonology and Allergology, Santaros Klinikos, Vilnius University Hospital, Vilnius, Lithuania;
${ }^{4}$ National Centre of Pathology, Affiliate of Santaros Klinikos, Vilnius University Hospital, Vilnius, Lithuania
}

\begin{abstract}
Background/Aim: The prognostic role of thyroid transcription factor-1 (TTF1) in advanced lung cancer is not clearly established. The present study aimed to evaluate the associations between clinicopathological characteristics, TTF1 expression, and overall survival (OS) of patients with advanced lung adenocarcinoma. Materials and Methods: One hundred and seventy-two patients were enrolled in this retrospective study. OS was assessed according to immunohistochemical TTF 1 expression in lung adenocarcinoma tissue, age, gender, performance status (PS), smoking history and status, disease stage, tumor differentiation, epidermal growth factor receptor (EGFR) mutation and EGFR tyrosine kinase inhibitor (TKI) treatment status. Results: The OS time was longer $(p<0.001)$ for patients with TTF1 expression than for patients without TTF1 expression (13.0 vs. 5.0 months, respectively). A multivariate analysis confirmed that worse PS [hazard ratio $(H R)=2.13, \quad p<0.001]$, poor histological differentiation $(H R=2.02, p=0.001)$, wild-type EGFR status (HR=3.08, $p<0.001)$ and negative TTF1 expression $(H R=1.97, p=0.001)$ were independent predictors of worse prognosis. Conclusion: TTF1 expression is an independent predictor of survival of patients with advanced lung adenocarcinoma.
\end{abstract}

Lung cancer is one of the most frequent types of cancer and causes death of more than 1.5 million people annually (1). The most predominant histological type of lung cancer is

This article is freely accessible online.

Correspondence to: Rolandas Zablockis, MD, Ph.D., Centre of Pulmonology and Allergology, Vilnius University Hospital Santaros Klinikos, Santariskiu str. 2, 08661 Vilnius, Lithuania. Tel: +370 68775633, Fax: +370 2365077, email: rolandas.zablockis@gmail.com

Key Words: Lung cancer, adenocarcinoma, pathology, prognostic factors. currently adenocarcinoma (2). The overall survival (OS) is poor for the majority of patients with adenocarcinoma despite advances in treatment (1).

In general, prognostic factors influencing survival in patients with lung adenocarcinoma have been identified: age, gender, weight loss, smoking status, performance status (PS), disease stage and number or site of metastases $(3,4)$. Some of these factors, such as disease stage and PS, are useful for choosing treatment options. However, the discriminant value of most potential prognostic biological markers is insufficient to predict the optimal therapeutic course for an individual $(5,6)$.

Epidermal growth factor receptor (EGFR) is an important therapeutic target for the treatment of lung cancer. Tyrosine kinase inhibitor (TKI) is recommended as first-line treatment for patients with $E G F R$-mutated non-small cell lung cancer (NSCLC), leading to a favorable response, better progressionfree survival and fewer side-effects than conventional chemotherapy. At present, EGFR mutation is widely used as a biomarker to select patients for EGFR-TKI treatment (7).

Thyroid transcription factor-1 (TTF1) is expressed by epithelial cells of thyroid and lung. TTF1 is a useful immunohistochemical (IHC) marker which helps distinguish lung adenocarcinoma from squamous cell carcinoma or large cell carcinoma and is also commonly used as a marker to distinguish between primary and metastatic lung adenocarcinoma (8).

Several studies have assessed the prognostic value of TTF1 in NSCLC, however, most of them included patients with early-stage disease $(9,10)$. The prognostic value of TTF1 expression in advanced NSCLC is controversial. Elsamany et al. in a retrospective study of 120 patients reported that TTF1 expression was not a prognostic marker in advanced non-squamous NSCLC (11).

A meta-analysis of 17 studies (including four studies of stage IIIb-IV NSCLC) suggested that TTF1 expression might be an important favorable prognostic factor for advanced- 
stage NSCLC. However, data from these studies were limited by patient heterogeneity. In addition, several relevant parameters were not included in multivariate analyses such as EGFR mutation status, type of therapy, or site and number of metastases (10).

The aim of this study was to evaluate associations between the clinicopathological characteristics, TTF1 expression, EGFR gene mutation status and OS of selected a patient population with stages IIIB and IV of primary lung adenocarcinoma.

\section{Materials and Methods}

Patients. A total of 172 consecutive patients with primary lung adenocarcinoma diagnosed in our Department from January 2012 to July 2017 were retrospectively selected. This cohort included only patients with stage IIIB or IV disease at initial diagnosis. All patients were treated in accordance with European Society of Medical Oncology guidelines for lung cancer $(12,13)$. The median follow-up period was 44 months (range $=6-104$ months).

Data for sex, age, smoking history and status, tumor-nodemetastasis (TNM) stage, and PS at the initial visit were obtained from the medical record. OS was calculated from the date of diagnosis until the date of death from any cause or the date of the last follow-up visit. Survival data were updated in February 2018.

Patients were categorized as never smokers if they smoked fewer than 100 cigarettes. Former smokers had quit smoking at least 1 year prior to the visit. Current smokers continued to smoke or had quit smoking less than one year prior to the visit (14). The clinical staging was performed according to the seventh edition of the TNM Classification for lung cancer (15). PS was estimated using the Eastern Cooperative Oncology Group (ECOG) scale (16).

The study was approved by Vilnius Regional Biomedical Ethics Committee (no. 158200-13-652-210), Vilnius, Lithuania. Written informed consent for participation was obtained from each patient.

Methods. Pathological tissue samples were obtained from each patient before treatment by brochoscopic biopsy. Lung adenocarcinomas were defined histologically according to the 2015 World Health Organization diagnostic criteria for lung carcinomas, and were classified into poorly, moderately and welldifferentiated (17). The diagnosis of lung adenocarcinoma in poorly differentiated TTF1-negative cases was confirmed if malignant epithelial lung tumors had signs of glandular differentiation or mucin production and cytokeratin 7 (CK7) expression, but were negative for $\mathrm{p} 40(8,18)$.

Immunohistochemical staining for TTF1 expression was carried out on formalin-fixed, paraffin-embedded tissue samples, using a standard streptavidin-biotin based method. The TTF1 antibody (SP141, rabbit monoclonal primary antibody; Ventana Medical Systems, Inc., Tucson, AZ, USA) was used at a dilution of $1 / 200$. In each case, normal alveolar cells (and thyroid tissue) were used as positive controls. Staining was considered positive when $10 \%$ or more of tumor cell nuclei reacted with any intensity (19) (Figure 1).

EGFR mutation status (exon 18-21 of the tyrosine kinase domain) was investigated by polymerase chain reaction and the direct DNA sequencing method. DNA was derived from tumor samples embedded in paraffin blocks. After de-paraffinization, tissue sections were stained with hematoxylin and eosin, and target lesions were selectively obtained. Details about the EGFR methodologies used for mutation detection were described previously (20).

Statistical analysis. Differences in clinical characteristics among TTF1 expression groups were tested using the chi-squared test. $p$ Values were calculated using Fisher's exact test. OS time was measured from the date of diagnosis until the date of death from any cause or last follow-up. Probability of survival was estimated using the Kaplan-Meier method. The log-rank test was used to determine survival differences between groups. Cox proportional hazards regression analysis was used to determine which independent factors had a significant impact on OS. All variables with a $p$-value of less than 0.05 at univariate analysis were entered into a multivariate analysis for which $p$-values of less than 0.05 were defined as being statistically significant. Data were analyzed using the Statistical Package for Social Science software version 21.0 for Windows (IBM Corp., Armonk, NY, USA).

\section{Results}

Patient demographics and pathological characteristics. Ninety-eight $(57.0 \%)$ patients were males and 74 patients $(43.0 \%)$ were females. The median patient age was 64 years (range $=29-84$ years). Ninety-three $(54.1 \%)$ patients were current or former smokers. The majority $(79.1 \%)$ of patients had an ECOG PS of 0-1. Pathologic stage was IIIB in 32 patients $(18.6 \%)$, and IV in 140 patients $(81.4 \%)$.

Platinum-based doublet chemotherapy (cisplatin and gemcitabine, carboplatin and gemcitabine, cisplatin and paclitaxel, carboplatin and paclitaxel, cisplatin and pemetrexed), single-agent chemotherapy (gemcitabine, vinorelbine) or single-agent targeted therapy (gefitinib, erlotinib) were administered to $81.9 \%, 5.3 \%$ and $12.8 \%$ of first-line treated patients respectively.

Second-line chemotherapy was received by $59.3 \%$ of the patients. Single-agent chemotherapy (docetaxel, pemetrexed, gemcitabine, vinorelbine) or platinum-based doublets (carboplatin and gemcitabine, carboplatin and paclitaxel, carboplatin and vinorelbine) were administered to $82.3 \%$ and $17.7 \%$ of second-line treated patients respectively.

Third-line chemotherapy was administered to $31.4 \%$ of the patients who received first-line chemotherapy. Singleagent chemotherapy (docetaxel, pemetrexed, gemcitabine, vinorelbine) accounted for about $88.9 \%$ of third-line treatments, and platinum-based doublet chemotherapy (carboplatin and gemcitabine, carboplatin and paclitaxel, carboplatin and vinorelbine) accounted for almost $11.1 \%$.

The adenocarcinomas were graded as $48(27.9 \%)$ cases of well-or moderately differentiated and $124(72.1 \%)$ of poorly differentiated. EGFR mutations (exon 18 in two cases, exon 19 in 10 cases, exon 20 in two cases, and exon 21 in 12 cases) were detected in $26(15.1 \%)$ patients. 


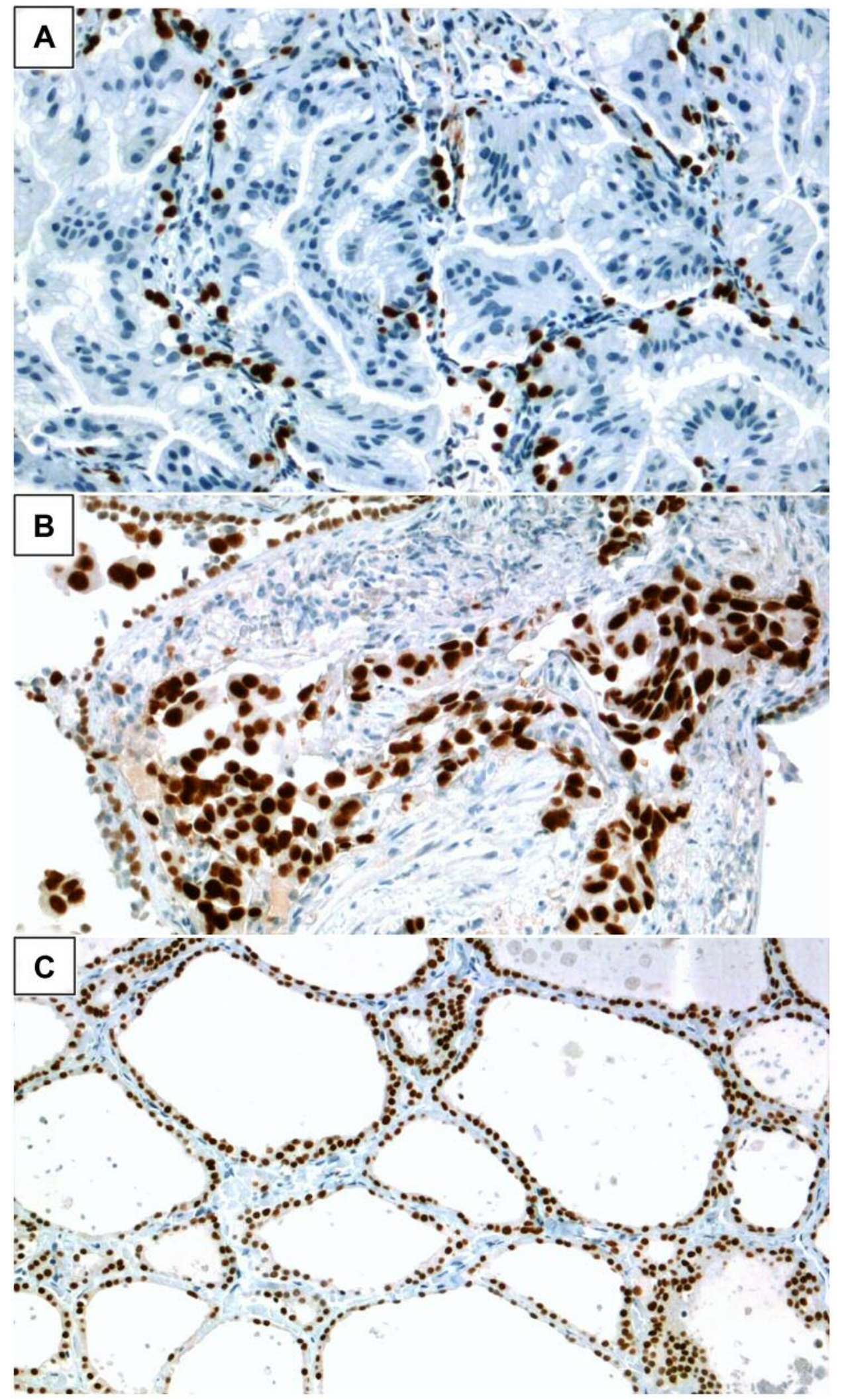

Figure 1. Representative negative $(A)$ and positive $(B)$ expression of thyroid transcription factor-1 (TTF1) in lung adenocarcinoma cells; thyroid tissue with positive TTF1 expression was used as positive control (C). Magnification $\times 200$. 
Table I. Characteristics of the patients with advanced-stage lung adenocarcinoma according to thyroid transcription factor-1 (TTF1) expression.

\begin{tabular}{|c|c|c|c|}
\hline Characteristic & $\begin{array}{l}\text { Without } \\
\text { TTF1 } \\
\text { expression } \\
(\mathrm{N}=38) \\
\mathrm{N}(\%)\end{array}$ & $\begin{array}{c}\text { With } \\
\text { TTF1 } \\
\text { expression } \\
(\mathrm{N}=134), \\
\mathrm{N}(\%)\end{array}$ & $\mathrm{p}$-Value \\
\hline Gender & & & $<0.001$ \\
\hline Male & $31(81.6 \%)$ & $67(50.0 \%)$ & \\
\hline Female & $7(18.4 \%)$ & $67(50.0 \%)$ & \\
\hline Age & & & 0.241 \\
\hline$\geq 70$ Years & $29(76.3 \%)$ & $92(68.7 \%)$ & \\
\hline$<70$ Years & $9(23.7 \%)$ & $42(31.3 \%)$ & \\
\hline Smoking status & & & $<0.001$ \\
\hline Never smokers & $8(21.1 \%)$ & $71(53.0 \%)$ & \\
\hline Current or former smokers & $30(78.9 \%)$ & $63(47.0 \%)$ & \\
\hline Clinical stage & & & 0.056 \\
\hline IIIB & $11(28.9 \%)$ & $21(15.7 \%)$ & \\
\hline IV & $27(71.1 \%)$ & $113(84.3 \%)$ & \\
\hline Histological differentiation & & & 0.015 \\
\hline Well-or moderately differentiated & $5(13.2 \%)$ & $43(32.1 \%)$ & \\
\hline Poorly differentiated & $33(86.8 \%)$ & $91(67.9 \%)$ & \\
\hline EGFR mutation & & & 0.008 \\
\hline Positive & $1(2.6 \%)$ & $25(18.7 \%)$ & \\
\hline Negative & $37(97.4 \%)$ & $109(81.3 \%)$ & \\
\hline ECOG PS & & & 0.132 \\
\hline $0-1$ & $33(86.8 \%)$ & $103(76.9 \%)$ & \\
\hline $2-3$ & $5(13.2 \%)$ & $31(23.1 \%)$ & \\
\hline EGFR-TKI treatment & & & 0.002 \\
\hline Yes & $0(0.0 \%)$ & $22(16.4 \%)$ & \\
\hline No & $38(100.0 \%)$ & $112(83.6 \%)$ & \\
\hline
\end{tabular}

ECOG PS, Eastern Cooperative Oncology Group performance status: $E G F R$, epidermal growth factor receptor; TKI, tyrosine kinase inhibitor. Chi-square test. $p$-Values were obtained by Fisher's exact test.
Table II. Results of univariate analysis.

\begin{tabular}{|c|c|c|}
\hline Characteristic & $\begin{array}{l}\text { Median overall survival, } \\
\text { months }(95 \% \mathrm{CI})\end{array}$ & $p$-Value \\
\hline Gender & & $<0.001$ \\
\hline Male & $8.0(6.1-9.8)$ & \\
\hline Female & $16.0(12.0-19.9)$ & \\
\hline Age & & 0.710 \\
\hline$\geq 70$ Years & $10.0(6.2-13.8)$ & \\
\hline$<70$ Years & $12.0(10.3-13.7)$ & \\
\hline Smoking status & & $<0.001$ \\
\hline Never smokers & $15.0(12.2-17.8)$ & \\
\hline Current or former smokers & $8.0(5.7-10.3)$ & \\
\hline Clinical stage & & 0.819 \\
\hline IIIB & $10.0(6.4-13.5)$ & \\
\hline IV & $12.0(10.2-13.8)$ & \\
\hline Histological differentiation & & $<0.001$ \\
\hline Well-or moderately differentiated & $20.0(13.0-26.9)$ & \\
\hline Poorly differentiated & $9.0(7.0-10.9)$ & \\
\hline EGFR mutation & & 0.001 \\
\hline Positive & $30.0(19.7-40.3)$ & \\
\hline Negative & $10.0(7.6-12.4)$ & \\
\hline ECOG PS & & 0.009 \\
\hline $0-1$ & $12.0(10.2-13.8)$ & \\
\hline $2-3$ & $5.0(3.3-6.7)$ & \\
\hline TTF1 expression & & $<0.001$ \\
\hline Positive & $13.0(11.0-14.9)$ & \\
\hline Negative & $5.0(2.9-7.0)$ & \\
\hline EGFR-TKI treatment & & $<0.001$ \\
\hline Yes & $33.0(27.6-38.4)$ & \\
\hline No & $10.0(7.7-12.3)$ & \\
\hline
\end{tabular}

ECOG PS, Eastern Cooperative Oncology Group performance status; TTF1, thyroid transcription factor-1; EGFR, epidermal growth factor receptor; TKI, tyrosine kinase inhibitor; CI, confidence interval. The logrank test was used to obtain $p$-values for comparing median survival.
Clinicopathological data and correlation with TTF1 expression. Overall, TTF1 immunoreactivity was found in 134 cases $(77.9 \%)$. The clinicopathological variables of the patients with lung adenocarcinoma, such as age, clinical stage grades and performance status were not significantly associated with TTF1 expression (Table I). Significant correlation was only found between TTF1 expression and female sex $(p<0.001)$, never-smoker status $(p<0.001)$, well-or moderately differentiated tumor $(p=0.015), E G F R$ mutation $(p=0.008)$ and treatment with EGFR-TKI $(p=0.002)$.

Only $2.6 \%$ of TTF1-negative patients had EGFR-mutant tumors. TTF1 positivity had $96.1 \%$ sensitivity, $25.3 \%$ specificity, 97.4\% [95\% confidence interval $(\mathrm{CI})=86.5-99.5 \%$ ] negative predictive value and $18.6 \%$ (95\% CI=12.9-26.1\%) positive predictive value for predicting the presence of activating mutations of EGFR.
Survival analysis. At end of the study, 156 out of 172 (90.7\%) patients were dead. The median patient OS was 11 months (range $=2-49$ months). In univariate analysis, sex, smoking and performance status, histological differentiation, EGFR mutation and TTF1 staining were statistically significantly $(p<0.05)$ correlated with OS (Table II).

The OS time was significantly (log rank test; $p<0.001$ ) longer for patients with adenocarcinoma with TTF1 expression (median=13.0 months; 95\% CI=11.0-14.9 months) than for those with adenocarcinoma without TTF1 expression (median=5.0 months; 95\% CI=2.9-7.0 months). For those with EGFR mutation, OS was statistically significantly (log-rank test; $p=0.001$ ) longer (median 30.0 months; 95\% CI=19.7-40.3 months) than for those with wild-type $E G F R$ (median=10.0 months; 95\% CI=7.6-12.4 months). The OS time was significantly (log-rank test; 
Table III. Multivariate analyses for overall survival.

\begin{tabular}{|c|c|c|}
\hline Characteristic & $\mathrm{HR}(95 \% \mathrm{CI})$ & $p$-Value \\
\hline \multicolumn{3}{|l|}{ Gender } \\
\hline Male $v s$. female & $1.10(0.70-1.73)$ & 0.674 \\
\hline \multicolumn{3}{|l|}{ Smoking status } \\
\hline Current or former smokers $v s$. never smokers & $1.34(0.88-2.05)$ & 0.168 \\
\hline \multicolumn{3}{|l|}{ Histological differentiation } \\
\hline Poorly differentiated $v s$. well-or moderately differentiated & $2.02(1.35-3.02)$ & 0.001 \\
\hline \multicolumn{3}{|l|}{ ECOG PS } \\
\hline $2-3$ vs. $0-1$ & $2.13(1.42-3.21)$ & $<0.001$ \\
\hline \multicolumn{3}{|l|}{ EGFR mutation } \\
\hline Negative $v s$. positive & $3.08(1.80-5.25)$ & $<0.001$ \\
\hline \multicolumn{3}{|l|}{ TTF1 expression } \\
\hline Negative $v s$. positive & $1.97(1.31-2.97)$ & 0.001 \\
\hline \multicolumn{3}{|l|}{ EGFR-TKI treatment } \\
\hline No vs. yes & $0.75(0.28-1.99)$ & 0.567 \\
\hline
\end{tabular}

ECOG PS, Eastern Cooperative Oncology Group performance status; TTF1, thyroid transcription factor-1; EGFR, epidermal growth factor receptor; TKI, tyrosine kinase inhibitor; CI, confidence interval, HR, hazard ratio. Cox proportional hazards regression analysis. HR >1.00 indicates worse survival.

$p<0.001)$ longer for patients treated with EGFR-TKI (median=33.0 months; 95\% CI=27.6-38.4 months) than for patients treated with chemotherapy (median $=10.0$ months; 95\% CI=7.7-12.3 months).

All variables with a $p$-value less than 0.05 at the time of univariate analysis (sex, smoking and performance status, histological differentiation, EGFR mutation, EGFR-TKI treatment and TTF1 staining status) were entered into a multivariate analysis. The multivariate analysis confirmed that worse PS, poor histological differentiation, wild-type EGFR and negative TTF1 expression were independent predictors of worse prognosis (Table III). In addition, the survival rate was not found to be significantly affected by smoking status, sex or EGFR-TKI treatment status.

The Kaplan-Meier OS survival curves according to TTF1 expression status, PS, histological differentiation, and EGFR mutation status are presented in Figure 2.

\section{Discussion}

TTF1 is a marker currently used in routine clinical practice to distinguish lung adenocarcinoma from adenocarcinoma metastatic to the lung. The role of TTF1 in differential diagnosis of lung adenocarcinoma is well documented, but its prognostic value, especially for patients with advancedstage lung cancer, has been less well studied.

The percentage of positive TTF1 expression reported in our study $(77.9 \%)$ is similar to that for Caucasian patients $(9$, 21). The definition of positive TTF1 expression under IHC study varies according to the study. Some studies defined positive TTF1 expression as any definite nuclear staining, whereas others defined it as tumors with $5 \%$ or $50 \%$ positivity (22-24). However, one study showed that the clinical outcome between patients with weakly TTF1-positive and those with strongly TTF1-positive adenocarcinoma was not different (21). Therefore, in this study, we defined positive TTF1 expression as reaction in $10 \%$ or more of tumor cell nuclei with any intensity.

Clinicopathological variables such as female sex, neveror former smoker status, well or moderately differentiated tumor and EGFR mutation were significantly associated with TTF1 expression. These results are in accordance with previously reported studies $(9,19)$.

A number of trials revealed PS and histological differentiation to be predictors of survival $(3,4,6,25)$. Similarly, in our study, worse PS (ECOG 2-3) and poor histological differentiation were independent predictors of worse prognosis.

There was no statistically significant difference in survival observed between never-or former smokers and current smokers in our study. A study by Li et al. reported similar findings (26). This suggests that detrimental effects of cigarette smoking may occur earlier in disease progression. Another explanation may be that the effects of continued smoking during therapy are not evident in patients treated with chemotherapy for late-stage disease as their duration of survival is limited (26).

TTF1 positivity in our study was associated with prolonged survival (13.0 vs. 5.0 months, $p=0.001)$. The estimated HR of 1.97 suggests that patients without TTF1 expression have a risk of death almost two times higher relative to patients with adenocarcinoma with TTF1 expression. After exclusion 

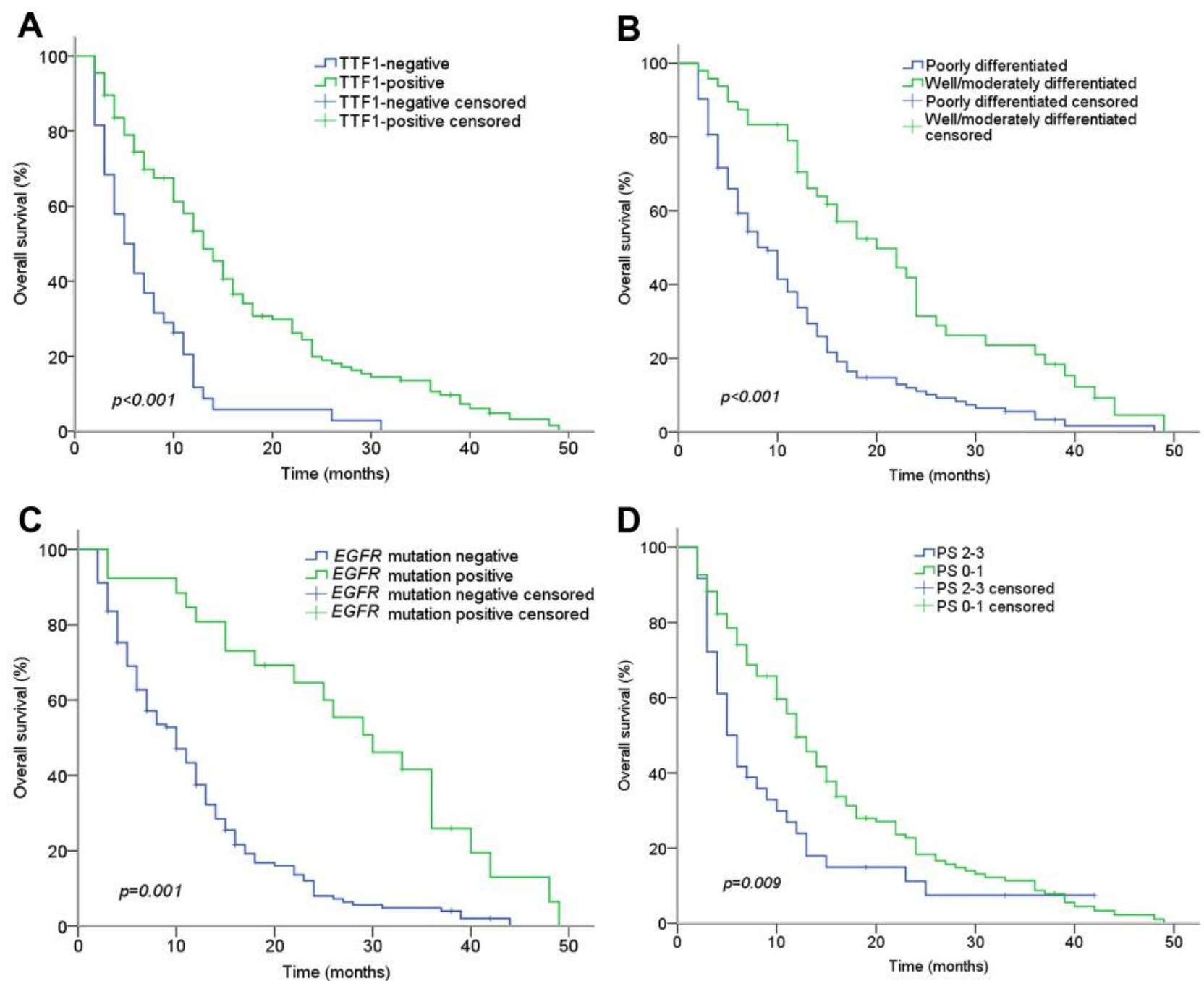

Figure 2. Overall survival curves for patients with advanced-stage lung adenocarcinoma (Kaplan-Meier plots) according to: A, thyroid transcription factor-1 (TTF1) expression: positive $(N=134)$ vs. negative $(N=38)$ groups; $B$, tumor differentiation: well-or moderately differentiated $(N=48)$ vs. poorly differentiated $(N=124)$ adenocarcinomas; $C$, epidermal growth factor receptor $(E G F R)$ mutation: positive $(N=26) v s . n e g a t i v e ~(N=146)$ groups; and. D, Eastern Cooperative Oncology Group performance status (PS): 0-1 (N=136) vs. 2-3 (N=36).

of EGFR mutation-positive patients in multivariate analysis (data not shown), we found that estimated HR for TTF1 expression decreased from 1.97 to 1.86 , but was still statistically significant $(p=0.003)$. Therefore, this did not have a significant impact on our results.

Several studies assessed the prognostic value of TTF1 in NSCLC, however, most of them included patients with earlystage disease. A meta-analysis published in 2006 noted that high TTF1 protein expression was associated with better survival in NSCLC, mainly in early-stage NSCLC. Favorable survival outcome associated with TTF1 expression in earlystage NSCLC may be explained by the lack of any adjuvant therapy in most of these patients and subsequently survival was less likely to be affected by other treatments, compared to surgical resection. This analysis included 10 studies and the data were insufficient to determine the prognostic value in lung adenocarcinoma and disease stage (9).

In a more recent meta-analysis including 17 studies with 2,235 patients, TTF1 overexpression was significantly correlated with favorable survival in patients with NSCLC and adenocarcinoma. This correlation was observed in both Asian and non-Asian study populations. When analysis was restricted to stage IIIB-IV NSCLC (4 studies), it was found that the combined HR (0.43) was lower than the combined HR (0.63) for studies of stage I NSCLC, suggesting that TTF1 expression might also be an important favorable prognostic 
factor for advanced-stage NSCLC. This systematic review with meta-analysis was complicated by heterogeneity between the studies. In addition, several relevant parameters were not included in multivariate analyses such as site and number of metastases, type of therapy, and EGFR mutation status. The technique used for IHC varied considerably among the studies. The primary antibodies used were not identical, and many different cut-offs for TTF1 positivity were used (10).

In contrast, Elsamany et al. in a retrospective study of 120 patients from Saudi Arabia reported that TTF1 expression was not a prognostic marker in advanced non-squamous NSCLC. Patients with stage IIIB-IV non-squamous NSCLC were enrolled in this study. TTF1-positive patients had better OS in univariate analysis, the significance of which was lost in multivariate analysis involving different prognostic factors (11). Several factors might explain the lack of association of TTF1 expression with survival improvement in that study. The percentage of patients with positive TTF1 expression $(83.3 \%)$ was similar to that of Asian patients. Forty percent of TTF1-positive patients were also EGFR-mutant. This may point to the possibility of biological similarity of NSCLC in Saudi Arabia with that of Asian patients (11).

Numerous studies reported the poor prognostic role of negative TTF1 expression in lung adenocarcinoma (9, 22, 24, 27). TTF1-negative patients define a subgroup of lung adenocarcinomas with unfavorable outcome, which may be because of the aggressive pattern of recurrence in such cases. Future studies are warranted to investigate molecular mechanisms of this poor prognosis and identify novel therapeutic targets to benefit more patients with this aggressive disease (27).

Assessment of EGFR mutations has become mandatory in order to choose the most active first-line treatment for patients with advanced primary lung adenocarcinoma (28). EGFR mutations were detected in 26 (15.1\%) from 172 lung adenocarcinomas patients in our study. The majority $(84.6 \%)$ of mutations were exon 19 deletions or mutation of exon 21 . These findings are in accordance with previous reports on Caucasian patients $(29,30)$.

However, almost all of the recently reported trials of treatment with TKIs demonstrated only progression-free survival benefits, and no OS benefits in patients with different $E G F R$ mutational status $(28,31,32)$. This is mostly because of the high crossover rate after progression $(31,32)$. Only one trial by Sellmann et al. showed a significant and clinical meaningful OS benefit in patients with EGFR mutation-positive NSCLC. Despite a high crossover rate $(53 \%)$ OS results of their study demonstrated a significant survival benefit for the gefitinib-treated patients with $E G F R$ mutation (46.9 vs. 21.0 months, $p=0.036$ ) (33).

Twenty-two out of 26 patients with EGFR-mutant (mutations exon 19 or 21) disease in our study received EGFR-TKI only in first-line treatment due to drug reimbursement policies in Lithuania. For this reason, EGFR-
TKI treatment crossover at disease progression was absent. This may explain the benefit to OS of treatment with TKIs in patients with EGFR mutation in our study.

Our data indicate that TTF1 negativity in patients with lung adenocarcinoma is negatively associated with EGFR mutation, which is in accordance with previous studies (19, 34). Only $2.6 \%$ of TTF1-negative patients were EGFRmutant. The negative predictive value of TTF1 for activating mutations of EGFR was $97.4 \%$. Prior studies showed that EGFR mutations are exceptionally rare in TTF1-negative adenocarcinomas of the lung $(35,36)$. The absence of TTF1 immunoreactivity can reliably predict an absence of activating mutations of EGFR. IHC is not able to replace mutational testing, but TTF1 status could be informative in the selection of patients for EGFR mutation testing (36).

In clinical practice, data on TTF1 expression combined with EGFR mutations can timely guide clinical treatment for lung adenocarcinomas (15). Such information could be used in the interpretation of equivocal EGFR mutation results or allow for early initiation of cytotoxic chemotherapy in patients newly diagnosed with TTF1-negative advancedstage adenocarcinoma of the lung when the wait for formal EGFR testing results could be detrimental (36). Negativity for TTF1 can also guide clinical testing toward biomarkers other than $E G F R$, improving the testing algorithm in patients with limited tumor tissue samples (19).

The limitation of this study is its retrospective design. Nevertheless, the study population was typical of that seen in everyday practice. Another limitation is that weight loss, adenocarcinoma histological subtypes, and metastatic site were not included in the analysis as they were not adequately reported in medical records for most of the patients.

In conclusion, the results of this study demonstrated that TTF1 expression is an independent predictor of survival of patients with advanced-stage lung adenocarcinoma. TTF1 expression status could be useful for predicting the presence of EGFR mutation. These results should be validated in a prospective study.

\section{References}

1 Fitzmaurice C, Dicker D, Pain A, Hamavid H, Moradi-Lakeh M, MacIntyre MF, Allen C, Hansen G, Woodbrook R, Wolfe C, Hamadeh RR, Moore A, Werdecker A, Gessner BD, Te Ao B, McMahon B, Karimkhani C, Yu C, Cooke GS, Schwebel DC, Carpenter DO, Pereira DM, Nash D, Kazi DS, De Leo D, Plass D, Ukwaja KN, Thurston GD, Yun Jin K, Simard EP, Mills E, Park EK, Catala-Lopez F, deVeber G, Gotay C, Khan G, Hosgood HD, 3rd, Santos IS, Leasher JL, Singh J, Leigh J, Jonas JB, Sanabria J, Beardsley J, Jacobsen KH, Takahashi K, Franklin RC, Ronfani L, Montico M, Naldi L, Tonelli M, Geleijnse J, Petzold M, Shrime MG, Younis M, Yonemoto N, Breitborde N, Yip P, Pourmalek F, Lotufo PA, Esteghamati A, Hankey GJ, Ali R, Lunevicius R, Malekzadeh R, Dellavalle R, Weintraub R, 
Lucas R, Hay R, Rojas-Rueda D, Westerman R, Sepanlou SG, Nolte S, Patten S, Weichenthal S, Abera SF, Fereshtehnejad SM, Shiue I, Driscoll T, Vasankari T, Alsharif U, Rahimi-Movaghar V, Vlassov VV, Marcenes WS, Mekonnen W, Melaku YA, Yano Y, Artaman A, Campos I, MacLachlan J, Mueller U, Kim D, Trillini M, Eshrati B, Williams HC, Shibuya K, Dandona R, Murthy K, Cowie B, Amare AT, Antonio CA, Castaneda-Orjuela C, van Gool CH, Violante F, Oh IH, Deribe K, Soreide K, Knibbs L, Kereselidze M, Green M, Cardenas R, Roy N, Tillmann T, Li Y, Krueger H, Monasta L, Dey S, Sheikhbahaei S, Hafezi-Nejad N, Kumar GA, Sreeramareddy CT, Dandona L, Wang H, Vollset SE, Mokdad A, Salomon JA, Lozano R, Vos T, Forouzanfar M, Lopez A, Murray C and Naghavi M: The global burden of cancer 2013. JAMA Oncol 1(4): 505-527, 2015.

2 Lewis DR, Check DP, Caporaso NE, Travis WD and Devesa SS: US lung cancer trends by histologic type. Cancer 120(18): 28832892, 2014.

3 Cuyun Carter G, Barrett AM, Kaye JA, Liepa AM, Winfree KB and John WJ: A comprehensive review of nongenetic prognostic and predictive factors influencing the heterogeneity of outcomes in advanced non-small-cell lung cancer. Cancer Manag Res 6: 437-449, 2014.

4 Maltoni M, Caraceni A, Brunelli C, Broeckaert B, Christakis N, Eychmueller S, Glare P, Nabal M, Vigano A, Larkin P, De Conno F, Hanks G and Kaasa S: Prognostic factors in advanced cancer patients: Evidence-based clinical recommendations - A study by the Steering Committee of the European Association for Palliative Care. J Clin Oncol 23(25): 6240-6248, 2005.

5 Donnem T, Bremnes RM, Busund LT, Andersen S and Pezzella $\mathrm{F}$ : Gene expression assays as prognostic and predictive markers in early-stage non-small cell lung cancer. J Thorac Dis 4(2): 212213, 2012.

6 Osarogiagbon RU: Predicting survival of patients with resectable non-small cell lung cancer: Beyond TNM. J Thorac Dis 4(2): 214-216, 2012.

7 Zappa C and Mousa SA: Non-small cell lung cancer: Current treatment and future advances. Transl Lung Cancer Res 5(3): 288-300, 2016.

8 Brunnstrom H, Johansson L, Jirstrom K, Jonsson M, Jonsson P and Planck $\mathrm{M}$ : Immunohistochemistry in the differential diagnostics of primary lung cancer: An investigation within the Southern Swedish Lung Cancer Study. Am J Clin Pathol 140(1): 37-46, 2013.

9 Berghmans T, Paesmans M, Mascaux C, Martin B, Meert AP, Haller A, Lafitte JJ and Sculier JP: Thyroid transcription factor 1 - a new prognostic factor in lung cancer: A meta-analysis. Ann Oncol 17(11): 1673-1676, 2006.

10 Zhan P, Qian Q, Wan B, Yan TD and Yu L-K: Prognostic value of ttf-1 expression in patients with non-small cell lung cancer: A meta-analysis. Translat Cancer Res 2(1): 25-32, 2013.

11 Elsamany SA, Al-Fayea TM, Alzahrani AS, Abozeed WN, Darwish W, Farooq MU, Almadani AS and Bukhari EA: Thyroid transcription factor-1 expression in advanced non-small cell lung cancer: Impact on survival outcome. Asian Pac J Cancer Prev 16(7): 2987-2991, 2015.

12 Besse B, Adjei A, Baas P, Meldgaard P, Nicolson M, Paz-Ares L, Reck M, Smit EF, Syrigos K, Stahel R, Felip E and Peters S: 2nd ESMO Consensus Conference on Lung Cancer: Non-smallcell lung cancer first-line/second and further lines of treatment in advanced disease. Ann Oncol 25(8): 1475-1484, 2014.
13 Felip E, Gridelli C, Baas P, Rosell R and Stahel R: Metastatic non-small-cell lung cancer: Consensus on pathology and molecular tests, first-line, second-line, and third-line therapy: 1st ESMO Consensus Conference in Lung Cancer; Lugano 2010. Ann Oncol 22(7): 1507-1519, 2011.

14 Nordquist LT, Simon GR, Cantor A, Alberts WM and Bepler G: Improved survival in never-smokers $v s$. current smokers with primary adenocarcinoma of the lung. Chest 126(2): 347-351, 2004.

15 Goldstraw P, Crowley J, Chansky K, Giroux DJ, Groome PA, Rami-Porta R, Postmus PE, Rusch V and Sobin L: The IASLC lung cancer staging project: Proposals for the revision of the TNM stage groupings in the forthcoming (seventh) edition of the TNM Classification of Malignant Tumours. J Thorac Oncol 2(8): 706-714, 2007.

16 Oken MM, Creech RH, Tormey DC, Horton J, Davis TE, McFadden ET and Carbone PP: Toxicity and response criteria of the Eastern Cooperative Oncology Group. Am J Clin Oncol 5(6): 649-655, 1982.

17 Travis WD, Brambilla E, Nicholson AG, Yatabe Y, Austin JHM, Beasley MB, Chirieac LR, Dacic S, Duhig E, Flieder DB, Geisinger K, Hirsch FR, Ishikawa Y, Kerr KM, Noguchi M, Pelosi G, Powell CA, Tsao MS and Wistuba I: The 2015 World Health Organization Classification of Lung Tumors. J Thorac Oncol 10(9): 1243-1260, 2015.

18 Mani $\mathrm{H}$ and Zander DS: Immunohistochemistry: Applications to the evaluation of lung and pleural neoplasms: Part 1. Chest 142(5): 1316-1323, 2012.

19 Shanzhi W, Yiping H, Ling H, Jianming Z and Qiang L: The relationship between TTF-1 expression and EGFR mutations in lung adenocarcinomas. PLoS One 9(4): e95479, 2014.

20 Smith GD, Chadwick BE, Willmore-Payne C and Bentz JS: Detection of epidermal growth factor receptor gene mutations in cytology specimens from patients with non-small cell lung cancer utilising high-resolution melting amplicon analysis. J Clin Pathol 61(4): 487-493, 2008.

21 Barletta JA, Perner S, Iafrate AJ, Yeap BY, Weir BA, Johnson LA, Johnson BE, Meyerson M, Rubin MA, Travis WD, Loda M and Chirieac LR: Clinical significance of TTF-1 protein expression and TTF-1 gene amplification in lung adenocarcinoma. J Cell Mol Med 13(8b): 1977-1986, 2009.

22 Barlesi F, Pinot D, Legoffic A, Doddoli C, Chetaille B, Torre JP and Astoul P: Positive thyroid transcription factor 1 staining strongly correlates with survival of patients with adenocarcinoma of the lung. Br J Cancer 93(4): 450-452, 2005.

23 Yatabe Y, Kosaka T, Takahashi T and Mitsudomi T: EGFR mutation is specific for terminal respiratory unit type adenocarcinoma. Am J Surg Pathol 29(5): 633-639, 2005.

24 Tan D, Li Q, Deeb G, Ramnath N, Slocum HK, Brooks J, Cheney R, Wiseman S, Anderson T and Loewen G: Thyroid transcription factor-1 expression prevalence and its clinical implications in non-small cell lung cancer: A high-throughput tissue microarray and immunohistochemistry study. Hum Pathol 34(6): 597-604, 2003.

25 Simmons CP, Koinis F, Fallon MT, Fearon KC, Bowden J, Solheim TS, Gronberg BH, McMillan DC, Gioulbasanis I and Laird BJ: Prognosis in advanced lung cancer-A prospective study examining key clinicopathological factors. Lung Cancer 88(3): 304-309, 2015. 
26 Li CT, Marek M, Guclu SZ, Kim Y, Meshref M, Qin S, Kadziola Z, Krejcy $\mathrm{K}$ and Altug S: Smoking and prognostic factors in an observational setting in patients with advanced non-small cell lung carcinoma. J Cancer 2: 52-61, 2011.

27 Zhang Y, Wang R, Li Y, Pan Y, Hu H, Zhang Y, Li H, Shen L, $\mathrm{Yu}$ Y, Sun Y and Chen H: Negative thyroid transcription factor 1 expression defines an unfavorable subgroup of lung adenocarcinomas. J Thorac Oncol 10(10): 1444-1450, 2015.

28 Haaland B, Tan PS, de Castro G, Jr. and Lopes G: Meta-analysis of first-line therapies in advanced non-small-cell lung cancer harboring EGFR-activating mutations. J Thorac Oncol 9(6): 805811,2014

29 Midha A, Dearden S and McCormack R: EGFR mutation incidence in non-small-cell lung cancer of adenocarcinoma histology: A systematic review and global map by ethnicity (MUTMAPII). Am J Cancer Res 5(9): 2892-2911, 2015.

30 Gahr S, Stoehr R, Geissinger E, Ficker JH, Brueckl WM, Gschwendtner A, Gattenloehner S, Fuchs FS, Schulz C, Rieker RJ, Hartmann A, Ruemmele $\mathrm{P}$ and Dietmaier W: EGFR mutational status in a large series of Caucasian European NSCLC patients: Data from daily practice. Br J Cancer 109(7): 1821-1828, 2013.

31 Kuan FC, Kuo LT, Chen MC, Yang CT, Shi CS, Teng D and Lee KD: Overall survival benefits of first-line EGFR tyrosine kinase inhibitors in EGFR-mutated non-small-cell lung cancers: A systematic review and meta-analysis. Br J Cancer 113(10): 1519$1528,2015$.
32 Guetz GD, Landre T, Uzzan B, Chouahnia K, Nicolas P and Morere JF: Is there a survival benefit of first-line epidermal growth factor receptor tyrosine-kinase inhibitor monotherapy versus chemotherapy in patients with advanced non-small-cell lung cancer? A meta-analysis. Target Oncol 11(1): 41-47, 2016.

33 Sellmann L, Fenchel K and Dempke WC: Improved overall survival following tyrosine kinase inhibitor treatment in advanced or metastatic non-small-cell lung cancer - The holy grail in cancer treatment? Transl Lung Cancer Res 4(3): 223-227, 2015.

$34 \mathrm{Kim}$ HJ, Choi EY, Jin HJ and Shin KC: Relationship between $E G F R$ mutations and clinicopathological features of lung adenocarcinomas diagnosed via small biopsies. Anticancer Res 34(6): 3189-3195, 2014.

35 Somaiah N, Fidler MJ, Garrett-Mayer E, Wahlquist A, Shirai K, Buckingham L, Hensing T, Bonomi P and Simon GR: Epidermal growth factor receptor $(E G F R)$ mutations are exceptionally rare in thyroid transcription factor (TTF-1)-negative adenocarcinomas of the lung. Oncoscience 1(8): 522-528, 2014.

36 Sheffield BS, Bosdet IE, Ali RH, Young SS, McNeil BK, Wong C, Dastur K, Karsan A and Ionescu DN: Relationship of thyroid transcription factor 1 to EGFR status in non-small-cell lung cancer. Curr Oncol 21(6): 305-308, 2014.

Received July 29, 2018

Revised September 12, 2018

Accepted September 19, 2018 